\title{
Impacts of the serum containing total flavonoids of Ajuga on rat glomerular mesangial cells
}

\author{
LIHONG NAN $^{1}$, MEI HUANG ${ }^{1}$, WENFANG LAI ${ }^{1}$, RU JIA $^{1}$, YANFANG ZHENG ${ }^{1}$, \\ LAN YANG $^{1}$, QINGQING XIE ${ }^{1}$ and WEIHUA PENG ${ }^{2}$ \\ ${ }^{1}$ College of Pharmacy, School of Pharmacy, Fujian University of Traditional Chinese Medicine, Fuzhou, Fujian 350122; \\ ${ }^{2}$ Department of Nephrology, Fuzhou General Hospital, Fuzhou, Fujian 350025, P.R. China
}

Received October 13, 2016; Accepted June 6, 2017

DOI: $10.3892 / \mathrm{mmr} .2017 .7194$

\begin{abstract}
The aim of the current study was to investigate the impacts and possible mechanisms of total flavonoids of Ajuga (TFA) on glomerular mesangial cells (GMC) through in vitro observations of the impacts of TFA-containing serum on GMC proliferation and extracellular matrix (ECM) secretion in lipopolysaccharides (LPS)-induced rats. Rat GMC was cultured in vitro, using LPS to stimulate the proliferation of GMC and the secretion of ECM; meanwhile, TFA-containing serum (TFA-S) was used for the intervention. Methyl thiazolyl tetrazolium (MTT) assay was performed to test the proliferation of GMC; enzyme-linked immunosorbent assay (ELISA) was used to detect the expressions of fibronectin (FN) and collagen IV (Col-IV) in cell supernatant, flow cytometry was performed to detect the cell cycle, and reverse transcription-polymerase chain reaction was performed to detect the expression levels of matrix metalloproteinase 9 (MMP-9) mRNA and transforming growth factor $\beta 1$ (TGF- $\beta 1$ ) mRNA. The GMC proliferation and the expressions of FN and Col-IV in cell supernatant were significantly reduced after 24 and $48 \mathrm{~h}$ TFA-S intervention $(\mathrm{P}<0.05$ or 0.01$)$. A total of $48 \mathrm{~h}$ subsequent to the intervention, the proportion of GMC in the $\mathrm{G}_{1}$ phase and the relative expression of MMP-9 mRNA were significantly increased $(\mathrm{P}<0.05$ or 0.01$)$, however the proportion of GMC in $\mathrm{S}$ phase and the relative expression of TGF- $\beta 1$ mRNA were significantly reduced $(\mathrm{P}<0.05$ or 0.01$)$. TFA-S can inhibit LPS-induced GMC proliferation and ECM accumulation, and its roles are associated with regulating the cell cycle and the expression levels of TGF- $\beta 1$ and MMP-9.
\end{abstract}

Correspondence to: Professor Weihua Peng, Department of Nephrology, Fuzhou General Hospital, 156 West 2nd Ring Road, Fuzhou, Fujian 350025, P.R. China

E-mail: weihuapengdoc@163.com

Key words: total flavonoids of Ajuga, glomerular mesangial cells, proliferation, extracellular matrix

\section{Introduction}

Mesangial proliferative glomerulonephritis (MsPGN) is a primary glomerular disease predominantly characterized by the proliferation of a group of diffuse glomerular mesangial cells (GMC) and various degrees of increasing of extracellular matrix (ECM), and is one of the most common pathological types of chronic glomerulonephritis (1). At present, there is no specific medical treatment against MsPGN, however, traditional Chinese medicine therapeutic strategies have achieved progress in the treatment of MsPGN, exhibiting certain advantages and potential against this disease.

GMC is the most active of the glomerular intrinsic cells, and has a variety of physiological and pathological functions; it is a target cell and an effector cell of a variety of noxious stimuli, and can secrete a variety of bioactive substances by autocrine or paracrine methods to affect the functions of itself or surrounding cells (2). Dysplasia of GMC, and the of resulting overproduction and accumulation ECM, may lead to glomerular sclerosis, therefore it is a central pathway through which glomerular diseases progress into end stage renal disease (3). At present, it is considered that GMC is in the key factor in nephritis (4). Therefore, inhibiting the proliferation of GMC has important significance in treating glomerular diseases, and is the key point in treating proliferative kidney diseases and preventing disease aggravation.

The cell cycle is the fundamental process of cellular life, and the regulation of cell proliferation occurs at the level of cell cycle. Transforming growth factor $\beta 1$ (TGF- $\beta 1$ ) is a class of multi-functional polypeptide growth factors, and as the key growth factor in regulating the proliferation and differentiation of tissue cells, it has important regulatory roles in the synthesis of ECM. TGF- $\beta 1$ can cause the accumulation of ECM through a variety of methods, among which regulating the expression and activity of the key enzymes that can degrade ECM, the matrix metalloproteinases (MMPs), is an important aspect (5). Numerous studies have confirmed that MMP-9 is the key protease to maintain the metabolic balance of ECMs, and TGF- $\beta 1$ and MMP-9 can regulate the expression and activity of one another (6-8).

Ajuga decumbens is the whole plant of Ajuga decumbens Thumb, an annual or perennial wild herb commonly identified throughout Fujian Province in China, and has multiple 
roles including reducing fever and inflammation, and inhibiting type I allergic reactions (9). Its active ingredients are flavonoids and due to the reductive phenolic hydroxyl group contained inside, flavonoids can directly clear oxygen free radicals and inhibit lipid peroxidation (10). Studies have demonstrated that free radicals and lipid peroxidation injury are involved in the pathological progression of glomerulonephritis, and are one of the pathogeneses (11). Therefore, the current study aimed to investigate whether total flavonoids of Ajuga (TFA) can effectively reduce urinary proteins in addition to blood urea nitrogen and serum creatinine in the MsPGN rat model, and promote the recovery of glomerular pathological changes. Its roles are suggested to be associated with anti-lipid peroxidation injury and the inhibition of the release of inflammatory cytokines (12), indicating that TFA has potential renal-protective effects. The in vitro culture of GMC is an essential means to study glomerular diseases and their development mechanisms. In the present study, in vitro experiments targeting GMC were performed so as to observe the impacts of TFA-S on lipopolysaccharides (LPS)-induced rat GMC proliferation, cell cycle, ECM secretion and the expression levels of MMP-9 and TGF- $\beta 1$, aiming to further investigate the impacts and possible mechanisms of TFA on GMC at cell biology and molecular levels, and to provide experimental basis for its further development and utilization.

\section{Materials and methods}

Animals. A total of 30 healthy clean-grade Sprague Dawley

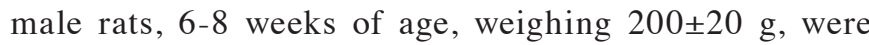
provided by Shanghai Slaccas Experimental Animal Co. Ltd. (Shanghai, China). The animals were fed in the experimental animal center of Fujian University of Traditional Chinese Medicine (Fuzhou, China) $\left(20-25^{\circ} \mathrm{C}\right.$, 50-70\% relative humidity). The design and implementation of animal experiments were in accordance with the relevant provisions, and were approved by the Ethics Committee of Fujian University of Traditional Chinese Medicine. The adaptable feeding was performed for a week before the experiment. The present study was conducted in strict accordance with the recommendations in the Guide for the Care and Use of Laboratory Animals of the National Research Council (13). The animal use protocol was reviewed and approved by the Institutional Animal Care and Use Committee of Fujian University of Traditional Chinese Medicine (Fuzhou, China).

Preparation of TFA. A total of $2 \mathrm{~kg}$ Ajuga decumbens (Medical Herb Station, Fuzhou, China) was added into water to soak it overnight, and then was decocted in 5 times volume of water for $1 \mathrm{~h}$ twice. Decocted fluids were combined and concentrated to $800 \mathrm{ml}$, then $75 \%$ ethanol was added and left overnight. The next day, the precipitation was removed, ethanol was recycled, and the remaining product was moved to the macroporous resin (Nanjing University Chemical Plant, Nanjing, China) adsorption column (enrichment of flavonoids). It was eluted with distilled water until the absence of Molisch's reaction, then it was eluted with 30, 50, 70 and $90 \%$ ethanol using 5 times the column volume. Subsequent to collection, the eluant was identified by color changes through the hydrochloric acid magnesium reaction, ethanol was recycled to a concentration of $3 \mathrm{~g}$ dose $/ \mathrm{ml}$. Subsequently, it was measured with rutin (China Institute of Pharmaceutical and Biological Products, Beijing, China) as the control by standard curve regression equation $(y=0.0108 x+0.0099$, the correlation coefficient $r=0.9993$ ). The TFA content was measured using the regression equation and flavonoids were obtained as $0.54 \mathrm{~g} / \mathrm{ml}$, which was equal to $3 \mathrm{~g}$ crude drug.

Preparation of test serum. The Sprague Dawley rats were randomly divided into the blank serum group and the TFA-S group ( $\mathrm{n}=15$ in each group). According to standard methodology, the rats in the TFA-S group were orally administered TFA solution twice [the effective dose indicated by early animal experiments was $2.16 \mathrm{~g} / \mathrm{kg}$ (12)] for three consecutive days, and the time interval between the two medications in the final day was $2 \mathrm{~h}$. A total of $1 \mathrm{~h}$ after the final medication, blood was sampled from all rats via the abdominal aorta, which was stood at room temperature for $4 \mathrm{~h}$, centrifuged at $700 \mathrm{x}$ g and room temperature for $15 \mathrm{~min}$, then the serum was separated under sterile conditions ( $\sim 2 \mathrm{ml}$ serum was extracted from each rat), inactivated in a $56^{\circ} \mathrm{C}$ constant temperature water bath for $30 \mathrm{~min}$, a positive pressure type needle filter was used to filter and sterilize, then the samples were stored at $-20^{\circ} \mathrm{C}$ for future use. The control group was only administered with equal volumes of distilled water, and the blood was sampled simultaneously with the TFA-S group using the same method.

Preparation and culture of cell lines. HBZY-1 (Biohermes Biological Medicine Technology Co., Ltd., Wuxi, China) cells were originally cultured in $25 \mathrm{~cm}^{2} / 50 \mathrm{ml}$ flasks filled with $10 \%$ fetal bovine serum (FBS)-containing RPMI1640 culture medium (Hyclone; GE Healthcare Life Sciences, Logan, UT, USA); following observation using an inverted phase contrast microscope (IX70; Olympus Corporation, Tokyo, Japan) and confirming good wall-adherent growth status, the flasks were placed in an incubator at $37^{\circ} \mathrm{C}$ and $5 \% \mathrm{CO}_{2}$ (HERA cell 150; Heraeus, Hanau, Germany) for 24 h. Subsequently the majority of the medium was discarded, and subsequent continuous culture was conducted in the incubator until $70-80 \%$ confluence was reached; GMC were then passaged and routinely cultured.

Detection of cell viability. The cell suspension was inoculated into 24-well plates (Corning Incorporated, Corning, $\mathrm{NY}$, USA) with $1 \times 10^{5}$ cells/well and was incubated for $24 \mathrm{~h}$ in a $\mathrm{CO}_{2}$ incubator $\left(5 \% \mathrm{CO}_{2}\right)$. Nutrient solution of RPMI1640 with $1 \%$ FBS was added to incubate cells for $24 \mathrm{~h}$, and GMC growth remained synchronous at $\mathrm{G}_{0}$ phase. Subsequently, 2.5, 5 and $10 \%$ TFA-S, respectively, was added to the cells, and the blank control group was simultaneously set, and 6-well plates were assigned by group. Cells were collected and trypan blue staining was conducted following the addition of TFA-S for 24 and $48 \mathrm{~h}$, respectively, and cells were counted (dead cells were dyed blue, and living cells were unstained). Cell viability was estimated according to the formula: Cell viability=Number of living cells/total cells x100\%.

Experimental grouping and treatment. GMC in the logarithmic growth phase were sampled from rats, digested with 
$0.25 \%$ trypsin (Hyclone; GE Healthcare Life Sciences), and then the cell suspension was prepared using $10 \%$ FBS-containing RPMI1640 culture medium. Subsequent to counted using the trypan blue staining method, the cells were seeded into 6-well or 96-well plates with the optimal cell density (Corning Incorporated) for $24 \mathrm{~h}$ culture in a $\mathrm{CO}_{2}$ incubator. After the cells completely adhered to the wall, the supernatant was discarded, and 1\% FBS-containing RPMI 1640 was added for another $24 \mathrm{~h}$ culture so as to synchronize GMC into $\mathrm{G}_{0}$ phase, which was then randomly divided into five groups, and applied different interventions factors: i) The control group, $10 \%$ normal rat serum added; ii) LPS group, LPS and $10 \%$ normal rat serum added; iii) $10 \%$ TFA-S group, LPS and $10 \%$ TFA-S added; iv) 5\% TFA-S group, LPS and 5\% TFA-S added; v) $2.5 \%$ TFA-S group, LPS and $2.5 \%$ TFA-S added. The final concentration of LPS was $10 \mu \mathrm{g} / \mathrm{ml}$, and the sample with the final serum concentration less than $10 \%$ was supplemented using normal rat serum. Each group was set as six parallel wells.

Detection of cell proliferation. The cell suspension was seeded into 96 -well plates $\left(3 \times 10^{3}\right.$ cells/well). Subsequent to 24 and $48 \mathrm{~h}$ TFA-S intervention, $20 \mu \mathrm{l}$ of $5 \mathrm{mg} / \mathrm{ml}$ thiazolyl blue tetrazolium bromide (MTT; Amresco LLC, Solon, OH, USA) was added to each well, followed by an additional $4 \mathrm{~h}$ incubation in the $\mathrm{CO}_{2}$ incubator. The supernatant was then carefully discarded from each well, $150 \mu$ l dimethyl sulfoxide was added (DMSO; Amresco), and the wells were agitated using an oscillator (IKA, Guangzhou, China) at $20 \mathrm{x} \mathrm{g}$ for $10 \mathrm{~min}$ so as to fully dissolve the crystals. The absorbance of each well (optical density, OD) was measured at $490 \mathrm{~nm}$ using a microplate reader (ELX800; BioTek Instruments, Inc., Winooski, VT, USA).

Detection of cell cycle. The cell suspension was seeded into 6 -well plates $\left(2 \times 10^{5}\right.$ cells/well), and after $48 \mathrm{~h}$ TFA-S intervention, the supernatant was discarded, followed by adding $0.25 \%$ trypsin to digest the specimens. The cells in each well were then collected into flow tubes, washed with pre-cooled phosphate-buffered saline (PBS; $4^{\circ} \mathrm{C}$ ) and centrifuged twice at $170 \mathrm{x} \mathrm{g}$ and $4^{\circ} \mathrm{C}$ for 5 min (supernatant absorption was removed), added with $1 \mathrm{ml}$ of the buffer solution (main components were citric acid, sodium sugar and DMSO) in the Cycle TESTTM plus DNA REAGENT KIT (BD Biosciences, Franklin Lakes, NJ, USA) and vortexed at low speed for $30 \mathrm{sec}$, and then centrifuged at room temperature (80 x g, $5 \mathrm{~min}$ ) and supernatant absorption was removed. After the buffer solution was discarded, $0.25 \mathrm{ml}$ of Solution A (containing trypsin fine amine hydrochloride buffer) was added to each tube at room temperature, followed by pipetting gently for $30 \mathrm{sec}$ and standing at room temperature for $10 \mathrm{~min}$, then $0.2 \mathrm{ml}$ Solution B (citrate buffer contained trypsin inhibitor and ribonuclease A) was added, followed by pipetting gently for $30 \mathrm{sec}$ and standing at room temperature for $10 \mathrm{~min}$. Subsequently, $0.2 \mathrm{ml}$ pre-cooled solution $\mathrm{C}$ (propidium iodide staining solution, $4^{\circ} \mathrm{C}$ ) was added to each well, followed by pipetting gently for $30 \mathrm{sec}$. Subsequently, the wells were filtered with $50 \mu \mathrm{m}$ nylon, and immediately placed into $4^{\circ} \mathrm{C}$ refrigerator for $1 \mathrm{~h}$ coloration in darkness. A flow cytometer (BD Biosciences) was then used to detect the cell cycle, and CellQuest software (version 3.0; BD Biosciences) was used to obtain the data for the analysis using ModiFit software (version 3.0; BD Biosciences).

Enzyme-linked immunosorbent assay (ELISA). After 24 and $48 \mathrm{~h}$ TFA-S intervention, the cell culture supernatant was collected, centrifuged at room temperature (1,000 x g, $10 \mathrm{~min})$ and the contents of fibronectin (FN) and collagen IV (Col-IV) were detected in the supernatant using ELISA according to the manufacturer's instructions (F1547 and F5734; Xitang Biotechnology Co., Ltd., Shanghai, China).

Reverse transcription-polymerase chain reaction (RT-PCR). The cell suspension was seeded into 6-well plates $\left(2 \times 10^{5}\right.$ cells/well), and after $48 \mathrm{~h}$ TFA-S intervention, the medium was discarded, followed by PBS washing three times and applying TRIzol (Invitrogen; Thermo Fisher Scientific, Inc., Waltham, MA, USA) to extract $1 \mu \mathrm{g}$ total RNA, which was then reverse transcribed into $2 \mu \mathrm{l} \mathrm{cDNA}$. The whole PCR reaction mixture was $20 \mu \mathrm{l}$, and the amplification conditions were as follows: Pre-denaturation at $94^{\circ} \mathrm{C}$ for $3 \mathrm{~min}$, denaturation at $94^{\circ} \mathrm{C}$ for $30 \mathrm{sec}$, annealing at $60^{\circ} \mathrm{C}$ for $30 \mathrm{sec}$, extension at $72^{\circ} \mathrm{C}$ for $30 \mathrm{sec}$, with a total of 35 cycles, and a final extension step at $72^{\circ} \mathrm{C}$ for $10 \mathrm{~min}$. The PCR products underwent gel electrophoresis using 2\% agarose (Gene Technology Co., Ltd., Shanghai, China), and then were imaged and the OD of the bands was analyzed using a one gel imager (Bio-Rad Laboratories, Inc., Hercules, CA, USA) and Quantity One software (version 4.6.5; Bio-Rad Laboratories, Inc.) with GAPDH as the internal control for correcting the OD values and calculating the relative expression levels of the target genes. The expression of each gene was based on the ratio of the OD of the target gene and the OD of the reference gene. The primers were synthesized by Sangon Biotech Co., Ltd. (Shanghai, China) and the sequences were as followed: GAPDH, forward 5'-CAAGGT CATCCATGACAACTTTG-3' and reverse 5'-GTCCACCAC CCTGTTGCTGTAG-3' (length, 496 bp); MMP-9, forward 5'-AAGGATGGTCTACTGGCAC-3' and reverse 5'-AGA GATTCTCACTGGGGC-3' (length, 280 bp); TGF- $\beta 1$, forward 5'-GCCTCCGCATCCCACCTTTG-3' and reverse 5'-GCG GGTGACTTCTTTGGCGT-3' (length, 396 bp).

Statistical analysis. Experiments were repeated 3 times and all results were expressed as the mean \pm standard deviation. Statistical analysis was conducted using one-way analysis of variance followed by the least significant difference test (when variance was homogenous) or Games-Howell test (when variance was nonhomogeneous). $\mathrm{P}<0.05$ was considered to indicate a statistically significant difference. All analyses were performed using SPSS software, version 15.0 (SPSS, Inc., Chicago, IL, USA). The correlation analysis used the Spearman rank correlation analysis.

\section{Results}

GMC viability. As presented in Fig. 1, cell viabilities in groups with 2.5, 5 and 10\% TFA-S for 24 and $48 \mathrm{~h}$ could achieve $96 \%$, and no significant difference was detected with the blank control group $(\mathrm{P}>0.05)$. These results indicated that 2.5, 5 and $10 \%$ TFA-S had not cytotoxic effect on rat GMC. 
GMC proliferation. In general, GMC adhered the wall after $24 \mathrm{~h}$ culture, and inverted phase contrast microscopy indicated that GMC was larger, and appeared as spindle-like, triangular, or an irregular star-like shape.

The results of MTT assay were presented in Fig. 2. Subsequent to 24 and $48 \mathrm{~h}$ LPS induction, the OD values of GMC were significantly increased compared with the control group $(\mathrm{P}<0.01)$, however the OD values of different TFA-S groups were significantly lower than LPS the group following 24 and $48 \mathrm{~h}$ TFA-S intervention ( $\mathrm{P}<0.05$ or 0.01 ).

As presented in Fig. 3, inverted phase contrast microscopy indicated that the proliferation of GMC was marked following $48 \mathrm{~h}$ LPS induction. Intensive cell growth, inter-cell contact disappearance and cell overlapping growth were observed. The cell proliferation was markedly inhibited following intervention with 10 and 5\% TFA-S for $48 \mathrm{~h}$; and the cells in the $2.5 \%$ TFA-S group additionally exhibited proliferation and overlapping growth following $48 \mathrm{~h}$ TFA intervention.

Cell cycle. The results of flow cytometry were presented in Fig. 4. Following $48 \mathrm{~h}$ LPS induction, the proportion of the cells in the $\mathrm{G}_{1}$ phase in the LPS group was decreased compared with the control group, however that in the $\mathrm{S}$ phase was increased $(\mathrm{P}<0.01)$, indicating that LPS can promote quiescent GMC to start the proliferation. Following $48 \mathrm{~h}$ intervention using 10, 5 and $2.5 \%$ TFA-S, the proportion of the cells in the $\mathrm{G}_{1}$ phase was increased, however that of the $\mathrm{S}$ phase was significantly reduced $(\mathrm{P}<0.05$ or 0.01$)$, suggesting that TFA can delay the transition of cells from $\mathrm{G}_{1}$ to $\mathrm{S}$ phase, namely TFA can inhibit the cell cycle of rat GMC.

Secretion of FN and Col-IV. The results of ELISA were presented in Fig. 5. The contents of FN and Col-IV in the cell supernatant of GMC following 24 and 48 h LPS induction were increased significantly compared with that of the control group $(\mathrm{P}<0.01)$, indicating that LPS can stimulate GMC to secrete ECM. Following 24 and $48 \mathrm{~h}$ intervention using 10 and 5\% TFA-S, the contents of FN and Col-IV in the cell supernatant were significantly reduced compared with the LPS group $(\mathrm{P}<0.05$ or 0.01$)$.

mRNA expression levels of MMP-9 and TGF- $\beta 1$. The results of RT-PCR were presented in Fig. 6. The relative expression of MMP-9 mRNA in the LPS group was significantly lower than the control group, however that of TGF- $\beta 1$ mRNA was significantly higher $(\mathrm{P}<0.01)$. The correlation analysis $(\mathrm{r}=-0.846$; $\mathrm{P}<0.05)$ indicated significant negative associations between their expression levels. Following intervention using 10, 5 and 2.5\% TFA-S, the relative expression of MMP-9 mRNA was significantly higher than the LPS group, however the relative expression of TGF- $\beta 1 \mathrm{mRNA}$ was significantly lower than that of the LPS group $(\mathrm{P}<0.05$ or 0.01$)$.

\section{Discussion}

Drugs orally administrated must be absorbed into the gastrointestinal tract, metabolized into active metabolites in vivo, and are then able to carry out their pharmacological effects. Serum pharmacology can objectively simulate the interactions between drugs and the body, and the pharmaceutical

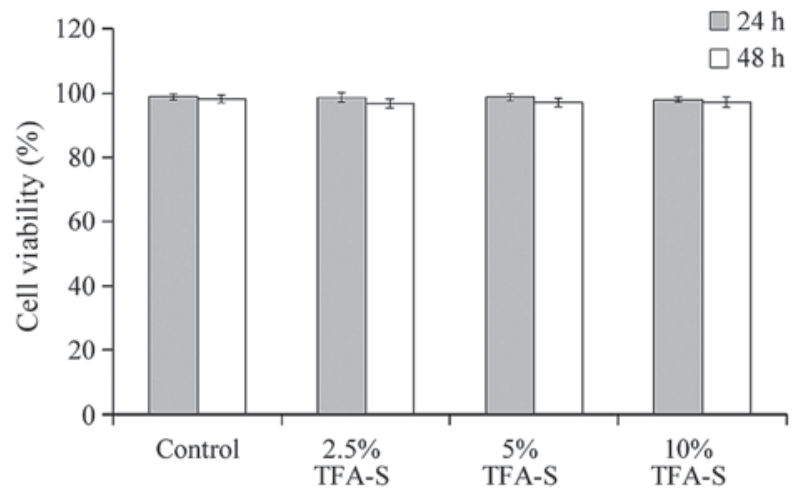

Figure 1. Impacts of TFA-S on viability of rat GMC. Rat GMCs were collected following treatment with TFA-S (2.5, 5 and 10\%) for 24 and $48 \mathrm{~h}$. The number of living cells was obtained by trypan blue stain. Cell viability was calculated as the number of living cells/total cells x100\%. All data are expressed as the mean \pm standard deviation. TFA-S, total flavonoids of Ajuga-containing serum; GMC, glomerular mesangial cells.

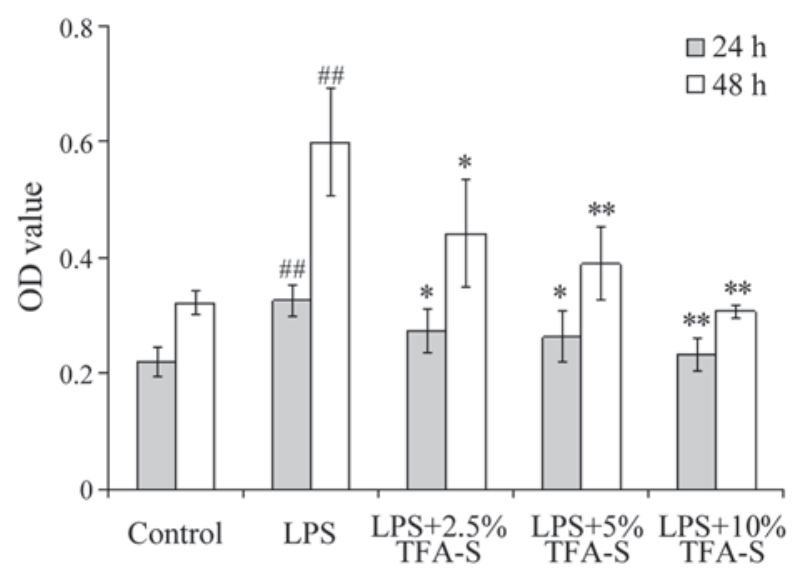

Figure 2. Impacts of TFA-S on proliferation of rat GMC. The MMT method was used to obtain the proliferation of LPS-induced rat GMC, which was regulated by TFA-S $(2.5,5$ and $10 \%)$ for 24 and $48 \mathrm{~h}$, at a wavelength of $490 \mathrm{~nm}$ using a microplate reader. All data were expressed as the mean \pm standard deviation. ${ }^{\# \#} \mathrm{P}<0.01$ vs. control group; ${ }^{*} \mathrm{P}<0.05,{ }^{* *} \mathrm{P}<0.01$ vs. LPS group. TFA-S, total flavonoids of Ajuga-containing serum; GMC, glomerular mesangial cells; LPS, lipopolysaccharides; OD, optical density.

ingredients contained in serum are also the endogenous active ingredients produced by the body under the reactions of active ingredients and drugs via a series of in vivo biotransformations. In addition, the physical and chemical properties of serum are similar to that of the internal environments in which the cells are present $(14,15)$. Therefore, if TFA directly acts on cells in vitro, the in vivo metabolic process will remain unclear, thus it cannot truly reflect the pharmacological effects of TFA in vivo. This experiment used TFA-S, therefore it can aid in the further exploration of the impacts and possible mechanisms of TFA on GMC.

Dysplasia of GMC serves important roles in the occurrence and development of glomerulitis and glomerulosclerosis. It has been confirmed that GMC hyperplasia is the initial factor of excessive secretion of mesangial matrix, and closely associated with the deposition of mesangial matrix $(16,17)$.

Cells undergo DNA synthesis and mitosis through the cell cycles. GMCs are a type of dormant cells, and mitogens 


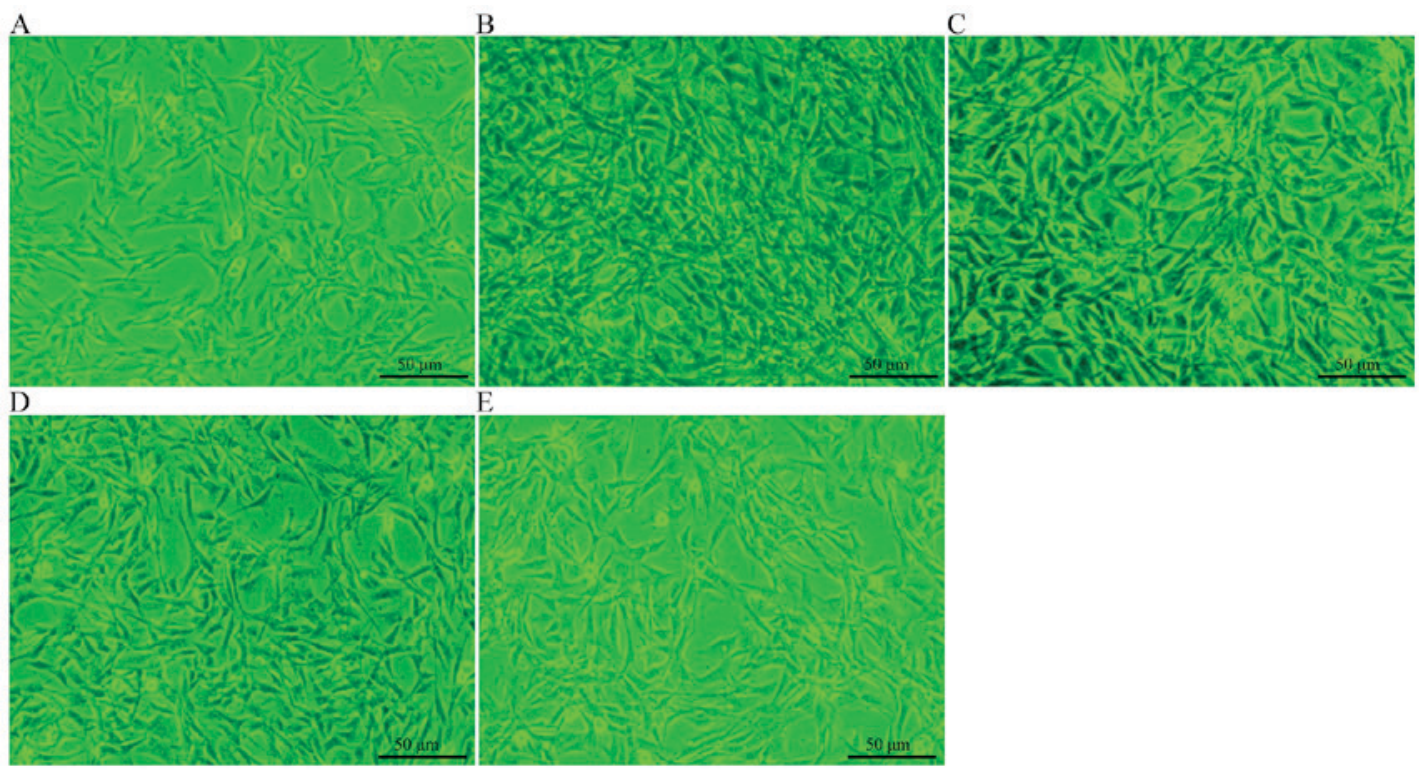

Figure 3. Morphology of GMC in different groups following $48 \mathrm{~h}$ TFA-S intervention. Inverted phase contrast microscopy was used to ascertain the proliferation of LPS-induced rat GMC exposed to TFA-S (2.5, 5 and $10 \%)$ for $48 \mathrm{~h}$. The proliferation of GMC was marked following LPS induction, with the appearance of intensive cell growth, inter-cell contact disappearance and overlapping cell growth; the cell proliferation was markedly inhibited following intervention with TFA-S. (A) Control group; (B) LPS group; (C) 2.5\% TFA-S group; (D) 5\% TFA-S group; (E) 10\% TFA-S group. Scale bar=50 $\mu \mathrm{m}$. TFA-S, total flavonoids of Ajuga-containing serum; GMC, glomerular mesangial cells; LPS, lipopolysaccharides.
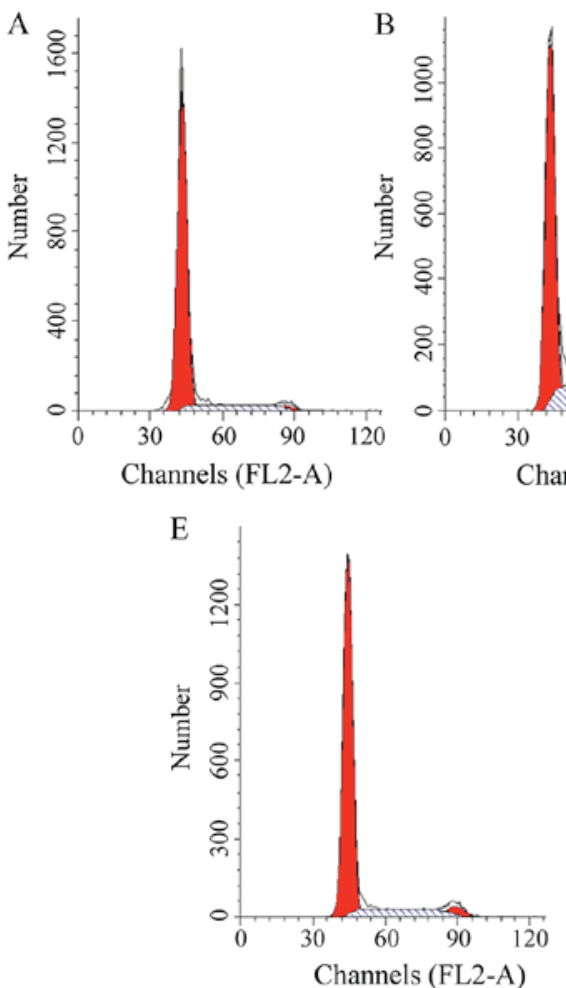
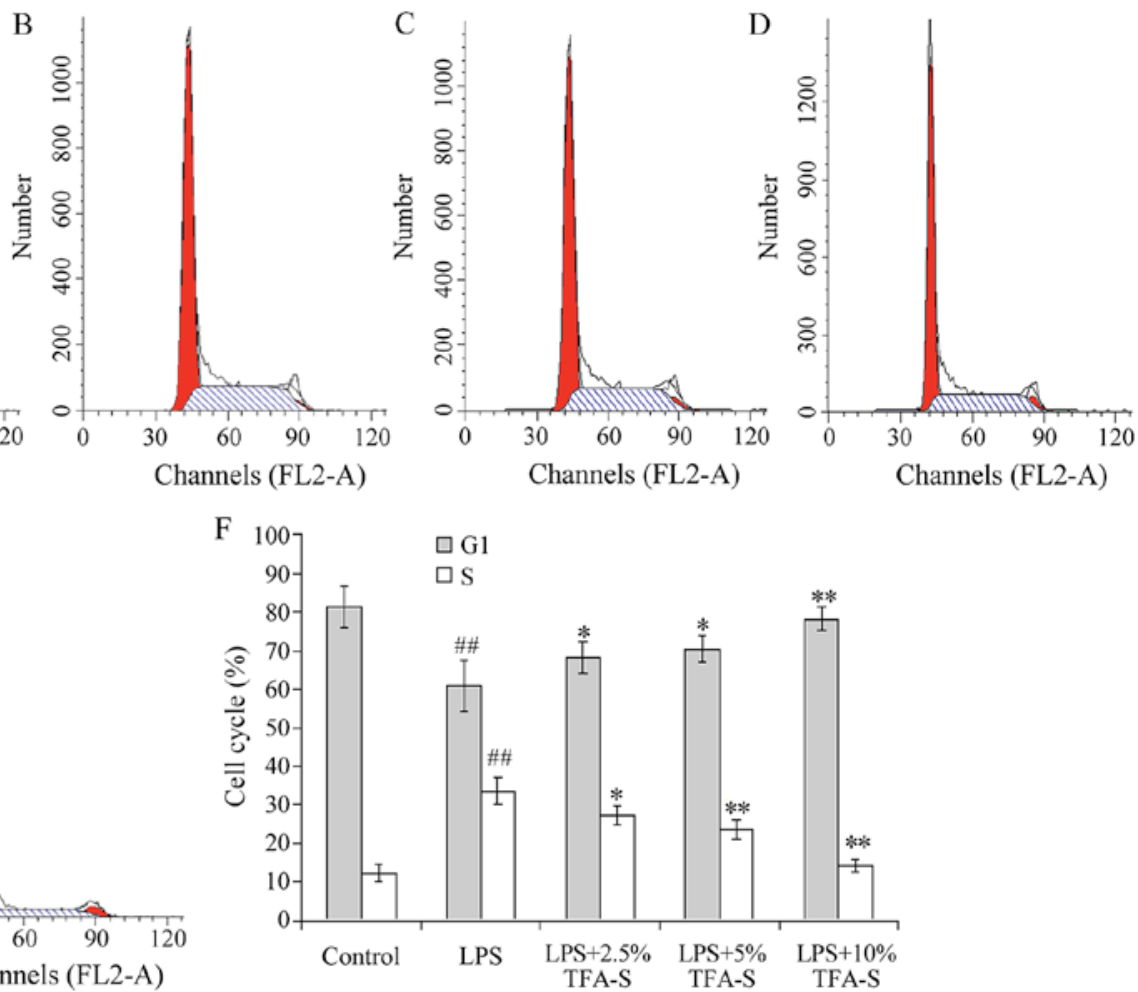

Figure 4. Impacts of TFA-S on the cell cycle of rat GMC. Flow cytometry was used to detect the cell cycle of LPS-induced rat GMC regulated by TFA-S (2.5, 5 and $10 \%$ ) for $48 \mathrm{~h}$. ModiFit, version 3.0 was used to obtain the percentage of the LPS-induced rat GMC which was under the $\mathrm{G}_{1}$ and $\mathrm{S}$ phase. All data are expressed as the mean \pm standard deviation. ${ }^{\# \#} \mathrm{P}<0.01$ vs. control group; ${ }^{*} \mathrm{P}<0.05,{ }^{* *} \mathrm{P}<0.01$ vs. LPS group. (A) Control group; (B) LPS group; (C) $2.5 \% \mathrm{TFA}-\mathrm{S}$ group; (D) 5\% TFA-S group; (E) 10\% TFA-S group; (F) cell cycle percentage. TFA-S, total flavonoids of Ajuga-containing serum; GMC, glomerular mesangial cells; LPS, lipopolysaccharides.

can stimulate the cells to leave the $\mathrm{G}_{0}$ phase and enter the $\mathrm{G}_{1}$ phase. Studies have indicated that there is one restriction point in the latter $G_{1}$ phase, and when the synthesis of regulatory proteins in the $\mathrm{G}_{1}$ phase accumulate to the point that pushes the cells to go beyond the $\mathrm{R}$ point, the cells subsequently complete the entire cell cycle independent from 

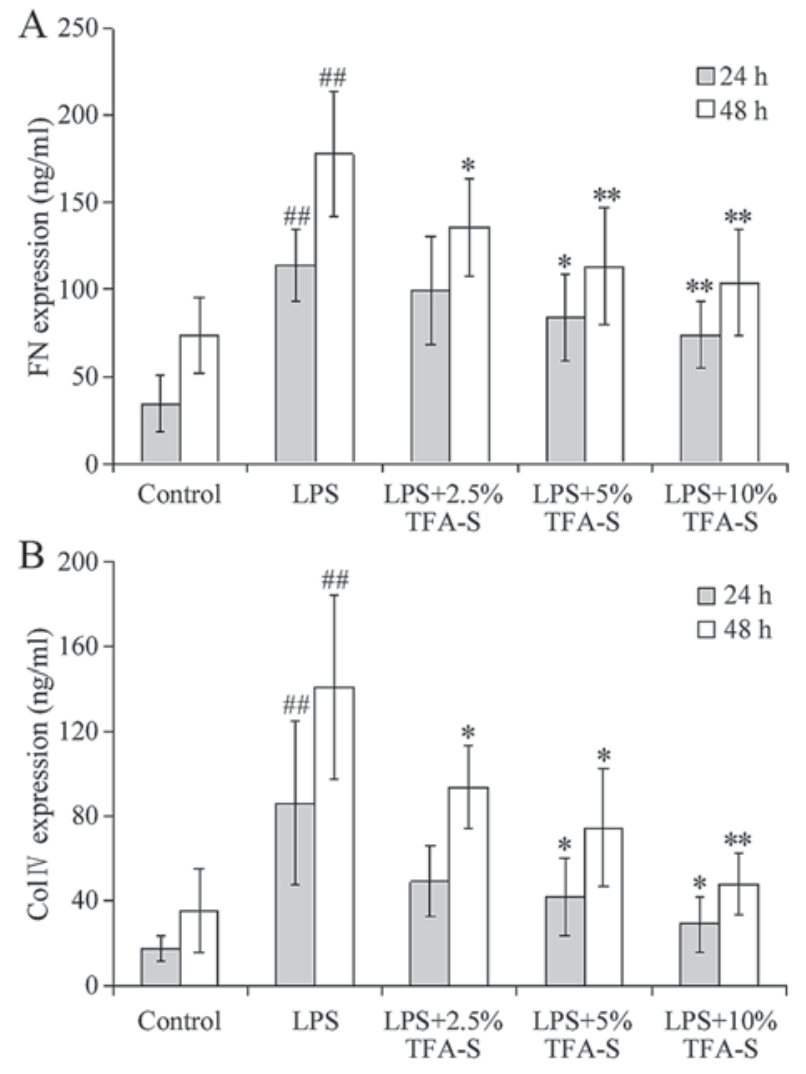

Figure 5. Impacts of TFA-S on expression levels of FN and Col-IV in the supernatant of rat GMC. ELISA was conducted in order to detect the secretion of extracellular matrix in LPS-induced rat GMC whose supernatant was collected following treatment with TFA-S $(2.5,5$ and $10 \%)$ for 24 and $48 \mathrm{~h}$. (A) Detection of FN content in the supernatant of each group. (B) Detection of Col-IV content in the supernatant of each group. All data are expressed as the mean \pm standard deviation. ${ }^{\# \#} \mathrm{P}<0.01$ vs. control group; ${ }^{*} \mathrm{P}<0.05,{ }^{* *} \mathrm{P}<0.01$ vs. LPS group. TFA-S, total flavonoids of Ajuga-containing serum; FN, fibronectin; Col-IV, collagen IV; GMC, glomerular mesangial cells; LPS, lipopolysaccharides.

extracellular growth-stimulating factors. Thus, the $\mathrm{G}_{1}$ phase is the stage that can control cell growth and decide cell fate, it is the critical and rate-limiting stage within the cell cycle. In the current study, rat GMCs were used as the target cell so as to explore the impacts of TFA-S on the proliferation of GMC at the cellular level, and the results suggested that LPS can induce abnormal proliferation of GMC, causing GMC to largely enter the $\mathrm{S}$ phase, namely the active proliferation phase. The 24 and $48 \mathrm{~h}$ intervention of 10, 5 and $2.5 \%$ TFA-S can inhibit the abnormal proliferation of LPS-induced GMC; furthermore, following $48 \mathrm{~h}$ intervention, it can significantly inhibit LPS-induced GMC to enter the $S$ phase from the $G_{1}$ phase, so the cell growth will be arrested in the $G_{1}$ phase, and the mitosis of GMC will be inhibited, thus achieving the purpose of inhibiting the proliferation of GMC.

ECM in normal renal glomeruli predominantly exists in the glomerular capillary loop basal membrane and mesangial area, thus constituting the basic network-like frame structure of glomerular basal membrane (GBM), and the synthesis and degradation imbalance of it will affect the molecular conformation and functional status of GBM (18). In a variety of human glomerular inflammatory diseases, the deposition of ECM predominantly appears the deposition of Col-IV, FN,
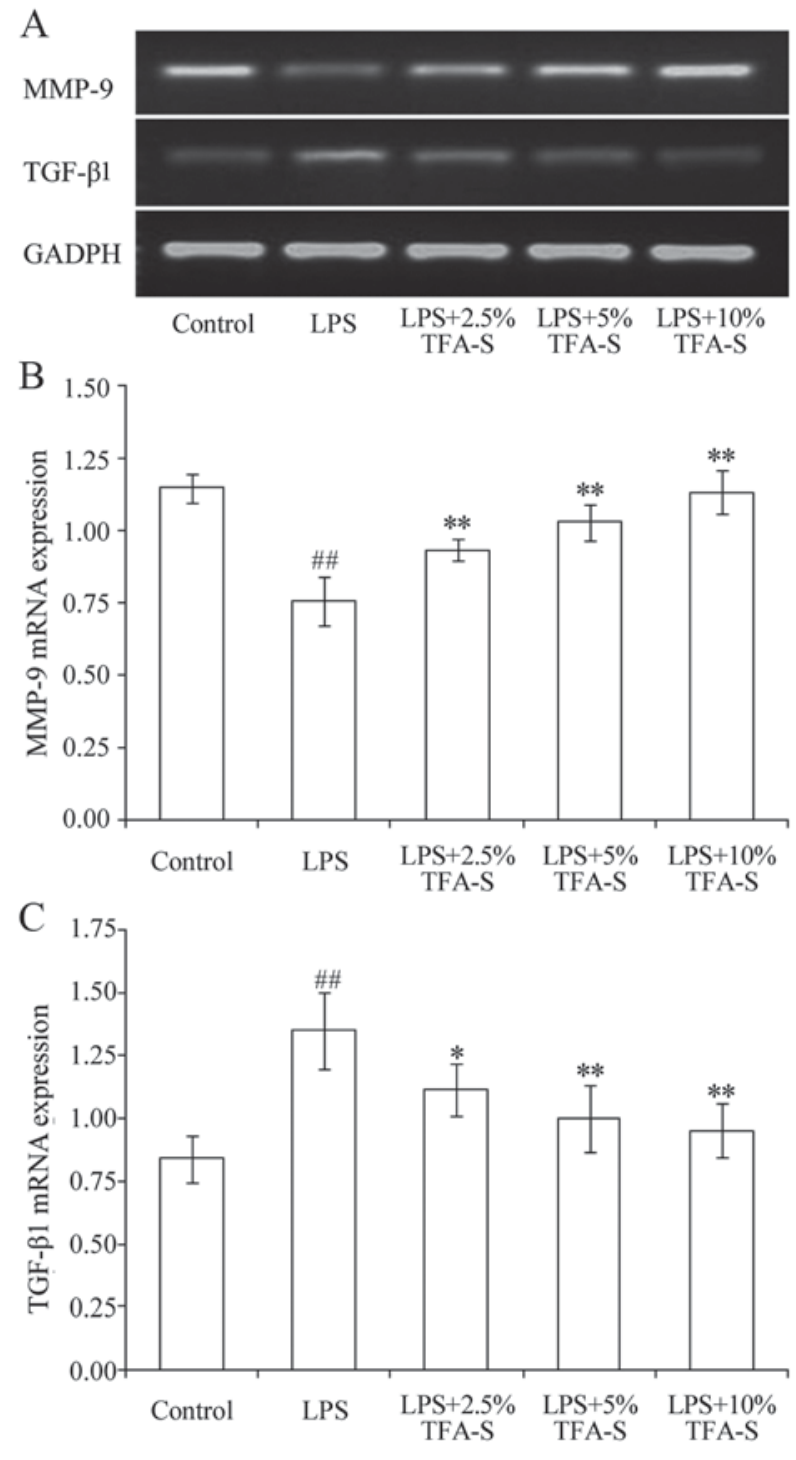

Figure 6. Impacts of TFA-S on mRNA expression levels of MMP-9 and TGF- $\beta 1$ of rat GMC. Total RNA in the LPS-induced rat GMC, which was regulated by TFA-S $(2.5,5$ and $10 \%)$ for $48 \mathrm{~h}$, was extracted and reverse transcription-polymerase chain reaction was applied in detecting gene expression. (A) Agarose gel electrophoresis. (B) MMP-9 and (C) TGF- $\beta 1$ expression measured by relative light density. GAPDH was used as the internal control. All data are expressed as the mean \pm standard deviation. ${ }^{\# \#} \mathrm{P}<0.01$ vs. control group; ${ }^{*} \mathrm{P}<0.05,{ }^{* *} \mathrm{P}<0.01$ vs. LPS group. TFA-S, total flavonoids of Ajuga-containing serum; MMP-9, matrix metalloproteinase 9; TGF- $\beta 1$, transforming growth factor $\beta 1$; GMC, glomerular mesangial cells; LPS, lipopolysaccharides.

or laminin (19). As an adhesive glycoprotein between cells and ECM, FN has significant abilities of combining fibrins and collagens, in addition to regulating the GMC growth and matrix synthesis, so it is an important component of ECM. During the development of glomerular lesions, $\mathrm{FN}$ is normally increased, and its changes occur early and significantly (20). Among the subsequently increased collagens, type IV and $\mathrm{V}$ account for the majority, and due to the fact that Col-IV accounts for approximately 50\% of the dry weight of the glomerular basal membrane, it penetrates the entire basal membrane, forms collagen fiber network among ECM and serves the role of mechanical barrier through combining cell adhesive molecules. The changes of Col-IV serve important 
roles in the development of kidney diseases. Thus, the ECM accumulation study focused upon the changes of FN and Col-IV

The results of the current study indicated that LPS can significantly stimulate GMC to secrete large amounts of FN and Col-IV, and the TFA-S interventions can significantly reduce the expression levels of FN and Col-IV, suggesting that TFA can inhibit the synthesis of ECM.

In normal glomeruli, GMC is located in the capillary wall, and is surrounded by outer basal membrane. On the internal side, endothelial cells separate it from the capillary cavity, and under in vivo physiological environments, the number, shape, and position of GMC appear relatively stable. In addition, it also has low proliferative activity, thus the level of ECM synthesis is low. Under pathological conditions, a variety of damaging factors and harmful substances can stimulate the activation of GMC, which can then result in abnormal proliferation and the secretion of various cytokines. These synthesized and secreted cytokines can then bind to the specific receptors on GMC, thus promoting the proliferation and activation of GMC via feedback. Therefore, one enhanced self-regulated GMC activity loop can be formed, and this loop can cause sustained GMC injury and ECM accumulation $(21,22)$. The accumulation and expansion of ECM can cause capillaries to be under pressure and a reduction in their filtration areas, followed by the deterioration of renal function. GMC secretes TGF- $\beta 1$, which is a multi-performance growth factor, serving important roles in the regulation of the proliferation of GMC, particularly the accumulation of ECM $(23,24)$. TGF- $\beta 1$ can affect the synthesis or degradation of ECM, thus gradually resulting in the synthesis and deposition of a large number of ECM proteins, in addition to the occurrence of glomerular sclerosis and renal failure (25), therefore it is known to be the strongest known renal pro-fibrosis cytokine.

The mechanisms of ECM deposition are complex, in which the dysfunction of MMPs and the tissue inhibitors of metalloproteinases serve key roles in the conversion process. MMPs are the only identified enzymes able to break down collagen fibers. MMP-9 is an important member of the MMP family, and its key substrates are type IV, V, VII and X collagen in addition to FN (26-28). Under pathological conditions, the abnormal expression of MMP-9 can cause the synthesis and degradation imbalance of type IV collagen and GBM remodeling disorders (29). The upregulation of MMP-9 in renal tissues can help to eliminate excessive ECM, so it exhibits a self-inhibiting effect against the formation of renal fibrosis.

TGF- $\beta 1$ is an important regulator of MMP-9, and is closely associated with the regulation of MMP-9 expression, in addition to the functional status and pathophysiological stages of disease of cells. The promoter regions of the majority of MMPs contain transforming growth factor inhibiting elements (TIE), and TGF- $\beta 1$ can combine with TIE, thereby inhibiting gene expression. For TIE-free MMP-9, its promoter region contains activator binding protein 1 (AP-1) (30). AP-1 is a heterodimer composed by c-fos and c-jun families via various combinations, including c-fos/c-jun, c-fos/JunD, or c-fos/JunB. c-fos/c-jun and c-fos/JunD induces gene transcription, while c-fos/JunB inhibits gene transcription (31). The results of the current study indicate that TGF- $\beta 1$ mRNA in GMC was significantly upregulated following 48 h LPS induction, however, the expression of MMP-9 mRNA was significantly downregulated; the correlation analysis $(\mathrm{r}=-0.846, \mathrm{P}<0.05)$ indicates significant negative associations between their expression levels, indicating that TGF- $\beta 1$ and MMP-9 may combine with the inhibitory AP-1 (c-fos/JunB) in the promoter region of MMP-9, there by inhibiting the transcription of MMP-9 gene, and this result is consistent with that of McLennan et al (32). TFA-S intervention can significantly decrease the expression of TGF- $\beta 1$ mRNA while increasing the expression of MMP-9 mRNA.

In conclusion, TFA-S can regulate the cell cycle, thus inhibiting LPS-induced abnormal proliferation of GMC. Furthermore, it can downregulate TGF- $\beta 1$ and upregulate MMP-9, inhibit the accumulation of ECM, downregulate TGF- $\beta 1$, reduce the promotive roles of TGF- $\beta 1$ on the proliferation and activation of GMC, aid in reducing continuous GMC damage, and delay the progression of chronic renal diseases. TFA can downregulate TGF- $\beta 1$ and inhibit the accumulation of ECM, thus exhibiting potential value in treating renal fibrosis, however, this requires further in-depth study.

\section{Acknowledgements}

The current study was funded by the Natural Science Foundation of Fujian Provincial Science and Technology Department (grant no. 2014J05094).

\section{References}

1. Geng W, Wei R, Liu S, Tang L, Zhu H, Chen P, WuJ, Zhang X, Zhu F, Yin Z and Chen X: Shenhua Tablet inhibits mesangial cell proliferation in rats with chronic anti-Thy-1 nephritis. Biol Res 49: 17, 2016.

2. Abboud HE: Mesangial cell biology. Exp Cell Res 318: 979-985, 2012.

3. Xie X, Peng J, Huang K, Huang J, Shen X, Liu P and Huang H: Polydatin ameliorates experimental diabetes-induced fibronectin through inhibiting the activation of NF- $\kappa \mathrm{B}$ signaling pathway in rat glomerular mesangial cells. Mol Cell Endocrinol 362: 183-193, 2012.

4. Scindia YM, Deshmukh US and Bagavant H: Mesangial pathology in glomerular disease: Targets for therapeutic intervention. Adv Drug Deliv Rev 62: 1337-1343, 2010.

5. Forbes JM, Fukami K and Cooper ME: Diabetic nephropathy: Where hemodynamics meets metabolism. Exp Clin Endocrinol Diabetes 115: 69-84, 2007.

6. Kobayashi T, Kim H, Liu X, Sugiura H, Kohyama T, Fang Q, Wen FQ, Abe S, Wang X, Atkinson JJ, et al: Matrix metalloproteinase- 9 activates TGF- $\beta$ and stimulates fibroblast contraction of collagen gels. Am J Physiol Lung Cell Mol Physiol 306: L1006-L1015, 2014.

7. Zhao H, Dong Y, Tian X, Tan TK, Liu Z, Zhao Y, Zhang Y, Harris DCH and Zheng G: Matrix metalloproteinases contribute to kidney fibrosis in chronic kidney diseases. World J Nephrol 2: 84-89, 2013.

8. Wang Y, Xu F, Chen J, Shen X, Deng Y, Xu L, Yin J, Chen H, Teng F, Liu X, et al: Matrix metalloproteinase-9 induces cardiac fibroblast migration, collagen and cytokine secretion: Inhibition by salvianolic acid B from Salvia miltiorrhiza. Phytomedicine 19: 13-19, 2011

9. Jin JS and Dou SH: Study on the flavonoids in the Ajuga decumbens. Anhui Med J 15: 51-52, 1994.

10. Testai L: Flavonoids and mitochondrial pharmacology: A new paradigm for cardioprotection. Life Sci 135: 68-76, 2015.

11. Ye T, Zhen J, Du Y, Zhou JK, Peng A, Vaziri ND, Mohan C, Xu Y and Zhou XJ: Green tea polyphenol (-)-epigallocatechin-3-gallate restores Nrf2 activity and ameliorates crescenticglomerulonephritis. PLoS One 10: e0119543, 2015.

12. Peng WH, Nan LH, Jia R, Fang TH, Wu FH and Xu ZT: Effects of TFA on IL-1 and TNF-alpha expression in mesangial proliferative glomerulonephritis rat. Lat Am J Pharm 34: 109-115, 2015. 
13. National Research Council (US) Institute for Laboratory Animal Research: Guide for the care and use of laboratory animals. Guide for the Care and Use of Laboratory Animals 103: 1072-1073, 1996.

14. Bochu W, Liancai Z and Qi C: Primary study on the application of Serum Pharmacology in Chinese traditional medicine. Colloids Surf B Biointerfaces 43: 194-197, 2005.

15. Gao SY, Gong YF, Sun QJ, Bai J, Wang L, Fan ZQ, Sun Y, Su YJ, Gang J and Ji YB: Screening antitumor bioactive fraction from Sauromatum giganteum (Engl.) Cusimano \& Hett and sensitive cell lines with the serum pharmacology method and identification by UPLC-TOF-MS. Molecules 20: 4290-4306, 2015.

16. Liu CM, Qi XL, Yang YF and Zhang XD: Betulinic acid inhibits cell proliferation and fibronectin accumulation in rat glomerular mesangial cells cultured under high glucose condition. Biomed Pharmacother 80: 338-342, 2016.

17. Paccosi S, Musilli C, Mangano G, Guglielmotti A and Parenti A: The monocyte chemotactic protein synthesis inhibitor bindarit prevents mesangial cell proliferation and extracellular matrix remodeling. Pharmacol Res 66: 526-535, 2012.

18. Hinderer S. Layland SL and Schenke-Layland K: ECM and ECM-like materials-Biomaterials for applications in regenerative medicine and cancer therapy. Adv Drug Deliv Rev 97: 260-269, 2016.

19. Kiliś-Pstrusińska K, Wikiera-Magott I, Zwolińska D, Kopeć W and Rzeszutko M: Analysis of collagen IV and fibronectin in blood and urine in evaluation of nephrotic fibrosis in children with chronic glomerulonephritis. Med Sci Monit 8: CR713-CR719, 2002.

20. Maeda A, Horikoshi S, Gohda T, Tsuge T, Maeda $K$ and Tomino Y: Pioglitazone attenuates TGF-beta(1)-induction of fibronectin synthesis and its splicing variant in human mesangial cells via activation of peroxisome proliferator-activated receptor (PPAR)gamma. Cell Biol Int 29: 422-428, 2005.

21. Ni WJ, Tang LQ, Zhou H, Ding HH and Qiu YY: Renoprotective effect of berberine via regulating the PGE2 -EP1-Gaq-Ca(2+) signalling pathway in glomerular mesangial cells of diabetic rats. J Cell Mol Med 20: 1491-1502, 2016.

22. Wu XM, Gao YB, Cui FQ and Zhang N: Exosomes from high glucose-treated glomerular endothelial cells activate mesangial cells to promote renal fibrosis. Biol Open 5: 484-491, 2016.
23. Jeong SI, Kwak DH, Lee S, Choo YK, Woo WH, Keum KS, Choi BK and Jung KY: Inhibitory effects of Cnidium officinale Makino and Tabanus fulvus Meigan on the high glucose-induced proliferation of glomerular mesangial cells. Phytomedicine 12: 648-655, 2005

24. Gonzalez-Ramos M, de Frutos S, Griera M, Luengo A, Olmos G, Rodriguez-Puyol D, Calleros L and Rodriguez-Puyol M: Integrin-linked kinase mediates the hydrogen peroxide-dependent transforming growth factor- $\beta 1$ up-regulation. Free Radic Biol Med 61: 416-427, 2013.

25. Krag S, Danielsen CC, Carmeliet P, Nyengaard J and Wogensen L: Plasminogen activator inhibitor-1 gene deficiency attenuates TGF-beta1-induced kidney disease. Kidney Int 68: 2651-2666, 2005

26. Bourboulia D and Stetler-Stevenson WG: Matrix metalloproteinases (MMPs) and tissue inhibitors of metalloproteinases (TIMPs): Positive and negative regulators in tumor cell adhesion. Semi Cancer Biol 20: 161-168, 2010.

27. Rohani MG and Parks WC: Matrix remodeling by MMPs during wound repair. Matrix Biol 44-46: 113-121, 2015.

28. Qin YH, Lei FY, Hu P, Pei J, Feng ZB and Pang YS: Effect of all-trans retinoic acid on renal expressions of matrix metalloproteinase-2, matrix metalloproteinase-9 and tissue inhibitor of metalloproteinase-1 in rats with glomerulosclerosis. Pediatr Nephrol 24: 1477-1486, 2009.

29. Bai Y, Wang L, Li Y, Liu S, Li J, Wang H and Huang H: High ambient glucose levels modulates the production of MMP-9 and a5(IV) collagen by cultured podocytes. Cell Physiol Biochem 17: 57-68, 2006.

30. Fisher EJ, McLennan SV, Yue DK and Turtle JR: High glucose reduces generation of plasmin activity by mesangial cells. Microvasc Res 53: 173-178, 1997.

31. Hess J, Angel P and Schorpp-Kistner M: AP-1 subunits: Quarrel and harmony among siblings. J Cell Sci 117: 5965-5973, 2004.

32. McLennan SV, Kelly DJ, Cox AJ, Cao Z, Lyons JG, Yue DK and Gilbert RE: Decreased matrix degradation in diabetic nephropathy: Effects of ACE inhibition on the expression and activities of matrix metalloproteinases. Diabetologia 45: 268-275, 2002. 